\title{
Venomous Stings and Bites in the Tropics (Malaysia): Review (Non-Snake Related)
}

\author{
Xin Y. Er ${ }^{1,2 *}$, Iman D. Johan Arief ${ }^{1,2}$, Rafiq Shajahan1, Faiz Johan Arief ${ }^{1}$, Naganathan Pillai1 \\ ${ }^{1}$ Monash University Malaysia, Selangor, Malaysia \\ ${ }^{2}$ Royal Darwin Hospital, Darwin, Australia \\ Email: *erxinyi@gmail.com
}

How to cite this paper: Er, X.Y., Arief, I.D.J., Shajahan, R., Arief, F.J. and Pillai, N. (2021) Venomous Stings and Bites in the Tropics (Malaysia): Review (Non-Snake Related). Open Access Library Journal, 8: e7230.

https://doi.org/10.4236/oalib.1107230

Received: February 8, 2021

Accepted: March 28, 2021

Published: March 31, 2021

Copyright $\odot 2021$ by author(s) and Open Access Library Inc.

This work is licensed under the Creative Commons Attribution International License (CC BY 4.0).

http://creativecommons.org/licenses/by/4.0/

\begin{abstract}
The success in conservation and increase in number of nature reserves resulted in repopulation of wildlife across the country. Whereas areas which are not conserved experience deforestation and destruction of animal's natural habitat. Both of these scenarios predispose mankind to the encounter of animals, some of which carry toxins and cause significant harm. This review dwells into the envenomation by organisms from the land and sea, excluding snakes which are discussed separately. Rapid recognition of the organism and rapid response may aid in further management and changes the prognosis of victims.
\end{abstract}

\section{Subject Areas}

Environmental Sciences, Toxicology, Zoology

\section{Keywords}

Venom, Toxins, Tropical, Malaysia, Bite

\section{Introduction}

Envenomation by animal is a common problem across all nations. The success in conservation and increase in number of nature reserves see the repopulation of wildlife across the country. This includes Malaysia, with its magnificent rainforests, mangrove swamps, beautiful seas and the rich biodiversity that lives in it. Unfortunately, some areas which are not conserved experience deforestation and destruction of animal's homeland. Both of these scenarios predispose mankind to the encounter of animals, some of which may carry poison or venom and cause significant harm.

It is important to clarify the definition of toxin, venom and poison which are 
easily confused with each other. Toxins are defined as compounds that chemically harm other organisms on a molecular level. It is an umbrella term that categorizes substances which cause pathophysiological damage to other organisms if exposed in biologically relevant amounts [1] [2]. Toxins are developed within living cells and are hence secreted by many microorganisms, invertebrates, plants and animals. These metabolic products have evolved in part due to the need for self-defence within these species [2]. Following this, venoms and poisons are both forms of toxins but differ in definition based on delivery and origins [2]. Similarly, they both encompass multiple and chemically distinct toxins [1]. However, the classical interpretation of poisons is toxins that are consumed or passively exposed over a period of time. Alternatively, venoms are toxins that are intentionally injected into another organism via specialized active apparatus. It is simply a poison that is biologically produced within organisms [2] [3]. Although the majority of these apparatus are spindle or needle-like in nature, some species may transfer their venom through toxin covered tentacles such as the Cnidaria species (Jellyfish, hydras, sea anemones and corals). Some organisms regularly bite or sting their provokers and this is seen in many land and sea animals (such as the spiders, bees and blue ringed octopus). Others inject their venom via forward facing holes at the tips of fangs (such as in the Naja Sp. of African spitting cobras) [4]-[9]. Hence, it is widely understood that a venomous animal is one that possesses a specialised gland and tissue to inject or transfer their biologically made toxin in the body of another organism. Fields of medicine and zoology often require these distinctions to help with toxicology and treatment. Malaysia, a country located in Southeast Asia, has a tropical climate that is teeming with a constellation of venomous land and sea creatures. This article explores the most current evidence available in symptomology, complications and management of patients who are exposed to these hazards, within Malaysia and South East Asia.

\section{Venomous Arthropods of Malaysia by Dr. Xin Y. ER}

Arthropod is the largest phylum group characterised by bilateral symmetry, segmented bodies, jointed paired appendages and hard exoskeleton [10]. As shown in Table 1, it that contains 25 orders, 10 of which has venomous or poisonous significance and more than 900,000 species [10] [11]. Only the orders that have medical significance are discussed here.

\subsection{Arachnida}

\subsubsection{Scorpions}

There are more than 1000 species of scorpions in the world but only 75 species have medical significance. The more lethal species from this spectrum are from the family Buthidae [11] [13]. Scorpions have 5 segments in their tail that ends with the telson (bulbous segment), a structure common to many arthropods. The venom apparatus is in the telson along with sensory hairs surrounding it [13]. Scorpions usually use their toxin to paralyse preys before extracting their 
Table 1. Taxonomy of arthropoda [12].

\begin{tabular}{|c|c|c|c|c|}
\hline Phylum & Sub-phylum & Class & Subclass & Examples \\
\hline \multirow{14}{*}{ Arthropoda } & \multirow{3}{*}{ Chelicerata } & \multirow{2}{*}{ Euchelicerata } & Arachnida & Spider, scorpions \\
\hline & & & Xiphosura & Horseshoe crab \\
\hline & & Pycnogonida & Pantopoda & Sea spiders \\
\hline & \multicolumn{4}{|l|}{ Crustacea } \\
\hline & \multirow{2}{*}{ Hexapoda } & Collembola & & Springtails \\
\hline & & Diplura & & \\
\hline & & \multirow{3}{*}{ Insecta } & archaeognatha & \\
\hline & & & dicondylia & Zygentoma \\
\hline & & & Pterygota & Winged insect \\
\hline & & Protura & & coneheads \\
\hline & \multirow{4}{*}{ Myriapoda } & Chilopoda & & centipedes \\
\hline & & Diplopoda & & millipedes \\
\hline & & Pauropoda & & \\
\hline & & Symphyla & & pseudocentipedes \\
\hline
\end{tabular}

haemolymph and body fluids. They also use their toxins for defensive purposes [14]. Scorpion toxins are species specific and complex. Some of the chemicals found in toxins are acetylcholinesterase, hyaluronidase, serotonin, phospholipase and neurotoxins [13]. The most potent are the neurotoxins which act by altering the ion channels leading to impairment of functions of various internal organs. Signs and symptoms vary depending on species, size of the scorpion and amount of venom injected, ranging from local intense pain and burning sensation to neurological or cardiovascular sequelae [14]. Fortunately, scorpion envenomation in Malaysia does not result in fatality. They merely cause sharp pain, swelling, numbness and paraesthesia of the limb [13] [14].

Spotted House Scorpion (Isometrus maculatus) is commercialized and although native to American tropics, can be seen in Southeast Asia [14]. It is usually less than $5 \mathrm{~cm}$ in length and has regular dark brown spots on a pale yellow undertone with slender claws [14]. Spotted House Scorpion has the most severe sting among all Malaysian scorpions. Black Scorpion (Heterometrus longimanus) is uniformly black, about $12 \mathrm{~cm}$ long excluding the claws (Figure 1). Its claws are bigger at the base which helps distinguish it from other species [14]. Its natural habitat is in the jungle or wooded country and can be found underneath logs. Wood Scorpion (Hormurus australasiae) is the most abundant and smallest in Malaysia. It is less than $3 \mathrm{~cm}$ long, black and flattened. It shares the same habitat as the black scorpions [14].

Scorpion stings in Malaysia can be treated with local wound care, pain management and tetanus prophylaxis [13]. Note that corticosteroids, calcium and antihistamine do not provide any benefits [13]. Generally, first aid measures 


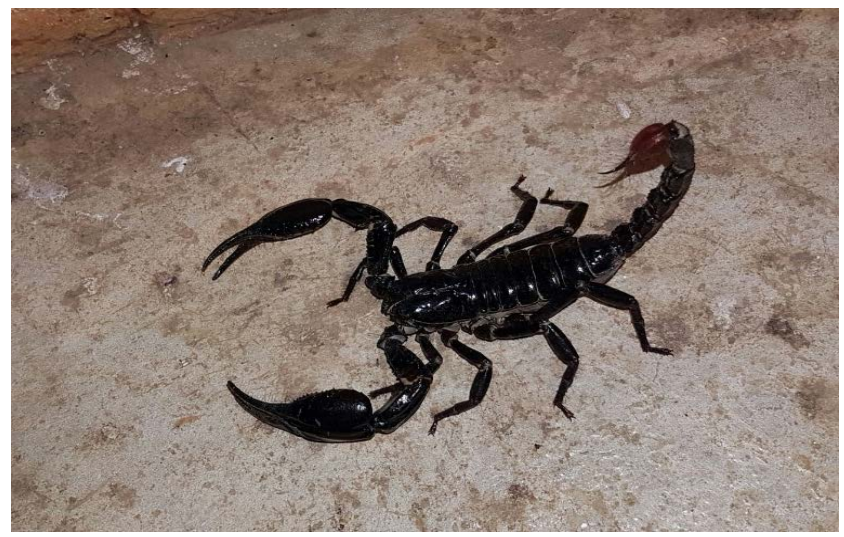

Figure 1. The black scorpion of Malaysia, (Heterometrus longimanus), assuming a defensive position with its stinger ready to strike.

include reassurance and creating a panic-free environment as it may reduce the absorption of the venom into the bloodstream. Local pain relief is crucial not only for the comfort of patient, but also as a means to avoid myocardial stress and reducing sympathetic nervous system activation. Ice pack applied at the site of sting can reduce swelling and dampen the rate of absorption of venom [14]. It is crucial to wear shoes and shake camping equipment before using to prevent scorpion sting.

\subsubsection{Spiders}

At least 200 out of roughly 30,000 species of spiders possess significant implications on human well-being [11]. It is known that all of these spiders with the exception of the Uloboridae family, produce neurotoxin designed to paralyze and kill preys [11] [13]. All spiders spin silk and possess a pair of curved fangs under their head which they use to inject their venoms [14]. Their toxins are also species specific and can be neurotoxic or cytotoxic [13].

As of recent years, brown widow spiders (Latrodectus geometricus) have been more commonly identified in Malaysia [15]. They are brown with black accents and have a dome shaped abdomen [15]. Their egg sac is spherical and spiky. The brown widow spiders can be found in urban areas around the house and garden. They lay eggs in door hinges, windows or ceilings [15]. Although the venom of the brown widow spider is as potent as their closely related cousins, the black widows (Latrodectus mactans), the brown widow spider is not able to inject as much venom, leading to less severe outcomes. A bite from the brown widow spider typically results in local pain and erythema [16].

Another spider to be concerned with is the yellow sac spider (Cheiracanthium) [14]. It is a small yellow spider with long legs. A bite usually causes swelling of the limb and surrounding lymph nodes with limited reports documenting occasions of difficulty in breathing; more research into this phenomenon is required [14].

Tarantulas (Mygalomorpha) are the largest and hairiest of spiders (Figure 2). They are popular as domestic pets and only bite when provoked [11] [13] [14]. 


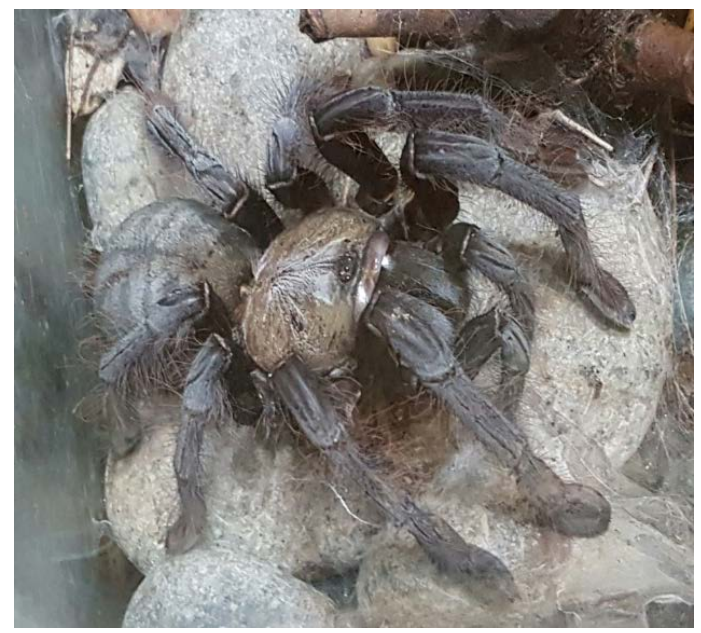

Figure 2. The Malaysian earth tiger tarantula has become somewhat popular in the pet industry due to its majestic and beautiful appearance. It is a priceless gem in the eyes of a true enthusiast. Nevertheless, they can deliver a nasty bite resulting in pain and localized oedema.

Tarantulas protect themselves through biting and bombarding victims with barbed urticating hairs [13]. Their venom contains hyaluronidase, nucleotides and polyamines to digest preys [13]. Tarantula bite results in puncture marks, deep throbbing pain and swelling [13] [14]. It can also cause necrosis of the skin around the bite or local tissue hypersensitivity in certain individuals resulting in itchiness [14]. Contact with urticating hairs may result in histamine release especially in the respiratory tract, eyes and skin, occasionally leading to mild bronchospasm and wheals [13].

In summary, all spiders in Malaysia have poisonous fangs and may bite, but serious medical attention is not routinely needed [14]. Treatment is supportive along with pain management, tetanus prophylaxis and cool compress to reduce swelling [13] [14]. Urticating hair can be removed with adhesives. Hypersensitivity should be treated with antihistamines or corticosteroids [13].

\subsection{Hymenoptera}

Hymenoptera genus has a sting at the tip of the abdomen (Table 2). A single sting can be severe and may lead to fatality especially if the victim progresses to systemic hypersensitivity ( $3 \%-4 \%$ of population) [17]. However, such cases are rare and are usually due to exposure to multiple stings [14]. In cases of multiple stings, victims usually have varying degrees of presentation and hypersensitivity reactions, ranging from self-limiting conditions to requiring intensive care. Symptoms often occur in this way as it following the body's reaction to histamine overdose [11] [14] [18]. Wasps and bee venom contain enzymes, biogenic amines and kinins that could result in the aforementioned reactions [17]. Examples of these biogenic amines are acetylcholine, histamine and serotonin, while examples of enzymes present in both are hyaluronidase and phospholipase A [19]. 
Table 2. Taxonomy of order hymenoptera with clinical significance [13].

\begin{tabular}{ccccc}
\hline Phylum & Class & Subclass & Order & Family \\
\hline \multirow{2}{*}{ Arthropoda } & Insecta & Pterygota & Hymenoptera & Vespidae (Wasps) \\
& & & & Apidae (Bees) \\
& & & Formicidae (Ants) \\
\hline
\end{tabular}

\subsubsection{Wasps (Vespidae)}

Wasps' venom contains peptides such as mastoparan and crabolin which result in the release of histamine whereas kinins such as apamin and melittin result in pain, increased vascular permeability and vasodilation [11] [19]. In addition, phospholipases and hyaluronidases aid in the breakdown of cellular membranes and connective tissues to increase venom diffusion [11]. The intense pain from the vespid sting is due to serotonin, acetylcholine, wasp kinins and antigen 5 (the latter also a potent allergen). Wasps are known to be more aggressive than bees and can sting multiple times [15].

A large study conducted in China discovered that fatal stings usually occur at the head and neck region. The causes of death due to wasp's stings are usually bronchoconstriction, laryngeal oedema and hypotension [18]. Majority of the victims suffer from toxic reaction and organ damage with acute kidney injury being the most commonly encountered end-organ damage. It is also noted that patients presenting with anaphylactic shock respond better and are generally easier to manage compared to non-anaphylactic shock victims [18].

The Banded Hornets (Vespa tropica) are large wasps with black and orange banded abdomens. It makes a paper-like nest in hollow trees or roof of a house. A single sting results in pain that can last several days [14]. Patient's suffering multiple stings require immediate hospital treatment as its complications may include hepatic dysfunction and rhabdomyolysis, frequently progressing to acute kidney injury [14] [19]. The Lesser Banded Hornet (Vespa affinis) is slightly smaller than banded hornet and the orange band extends further forward. Its nest is usually in the open on the bough of trees or in the bushes. Effects of the sting are similar to banded hornets [14].

The Banded Polistes (Polistes saggitarius) is similar in colour to the banded hornet, however, it has a slender body and long legs that hang down during flight [14]. Its nest can be found in bushes or hanging from the cave of buildings [14]. They are essentially more aggressive and their stings are often painful and severe. Multiple stings from the polistes can result in myasthenia gravis and thrombocytopenic purpura [19].

Asian hornets (Vespa velutina) live in places above 1250 metres and have a golden-brown abdomen with little black marks [14]. It is the most aggressive wasp in Malaysia [23]. Stings usually result in pain and swelling [14]. Wasps from genus Ropalidia builds their nests on twigs, leaves and herbage [14]. The night wasps (Provespa anomala) flies at night and is attracted to light, therefore it can be found entering one's home [14]. It is slender and has rusty brown colour. 
The Solitary Wasps builds nests and keeps their food in it by paralyzing their victim through sting and preserving them alive [14]. The larvae then eat the prey. The largest solitary wasp is spider-hunters (pompilidae). Customarily, solitary wasps are not dangerous as they only sting once rather than multiple times [14].

\subsubsection{Bees (Apidae)}

There are 3 major proteins in bee's venom, namely melittin, hyaluronidase and phospholipase A2 that can cause ailments in most of the population [13]. Bee stings usually result in acute onset burning or sharp pain with slight erythema and oedema. Bees usually sting only in defence and some species die as a result of evisceration [20]. Biologically, the component mellitin hydrolyses cell membranes, altering its permeability. It also induces histamine and catecholamine release. Together with phospholipase A2, it results in arachidonic acid release which breaks down the cell membrane, and sets in the inflammatory cascade. Peptide 401 results in mast cell degranulation, thus releasing histamine and other vasoactive amines. Sequentially, significant hypotension with life threatening arrhythmias may develop following the release and interaction of these vasoactive peptides [20].

The Giant Honeybee (Apis dorsata) is a large bee with yellow patches on its abdomen [14] (Figure 3). It is commonly found in Malaysia and makes huge hanging combs up to 2 metres long. It is usually known for being a docile insect, however if provoked, the bees may swarm and sting.

\subsubsection{Treatment of Stings}

The most active component in the stings of wasps and bees is histamine. Hence it can be treated effectively with antihistamines in any route [14]. Ice packs can also be used to minimize swelling. Stingers can be removed by scraping with a scalpel or credit card [13]. However, if there are signs of allergy or systemic hypersensitivity such as difficulty breathing or angioedema, immediate medical attention is warranted [14]. Should there be any respiratory or cardiovascular manifestations indicating anaphylaxis, rapid intramuscular epinephrine is indicated.

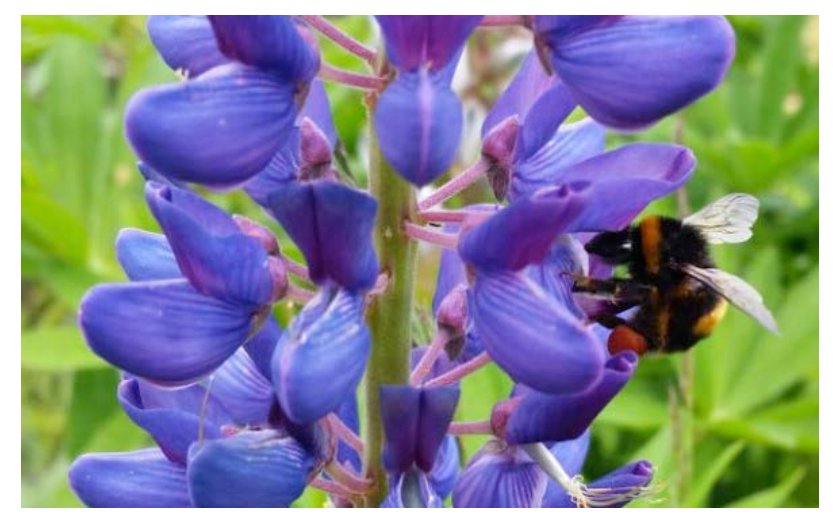

Figure 3. A bumblebee species is seen on a flower, collecting its pollen with a pollen basket easily seen at its hind legs. 
Immunotherapy is another form of treatment for those that are specifically allergic to hymenoptera venom [20]. It provides complete immunity towards yellow jackets venom allergy and around $75 \%$ to $80 \%$ immunity to bee venom allergy [20]. Despite its novelty, it is extremely expensive and thus is generally reserved for those with severe anaphylaxis manifestation or those that come into close contact with the said bees or wasps on a daily basis [20]. Interestingly, Malaysia offers apitherapy where bee stings are used to treat inflammatory and degenerative connective tissue diseases, neurological disorders, auto-immune diseases and can help prevent certain cancers [17]. Nonetheless, more robust research and studies are required to confirm the efficacy of apitherapy.

\subsubsection{Ants (Formicidae)}

Ants are social insects that defend their nests by biting or stinging [14]. Their length varies from less than $1.5 \mathrm{~mm}$ to over $35 \mathrm{~mm}$ [11]. The only ant of concern is the weaving ant (Oecophylla smaragdina) or natively known as "Kerengga" [14]. It is a rusty red long-legged ant and commonly found in mangrove areas [14]. Weaving ants attack viciously by biting and ejecting acid fluid over the wounds when their nest is disturbed [14].

Fire ants (Solenopsis) possess a sting and are black in colour with segments of rusty brown. They can be found under logs, stone and nests in soil near moist areas [11] [14]. Their sting is rich in alkaloids such as 2,6-disubstituted piperidine that has antibacterial, cytotoxic, haemolytic and insecticidal properties [13]. Symptoms of ant bite are often classified into local, large local and systemic symptoms. Local reactions occur in non-allergic individuals whereas a large local reaction is defined by a pruritic painful swelling more than $5 \mathrm{~cm}$ in diameter. Systemic reactions occur remotely from sting sites on the patient [13]. This toxin results in pain and a burning sensation. It may then become an umbilicated pustule [11] [14]. Severe reactions lead to tissue swelling capable of compromising blood flow to limbs [13]. Cold compresses and pain management can be used for local reactions along with cleaning using water and soap. Large local reactions may require antihistamine or corticosteroids whereas intravenous or subcutaneous epinephrine should be used for systemic reactions [13].

\subsection{Lepidoptera}

The larvae of some moths have a coat of hair or fine spines that can cause rashes or burning pain. Their toxins are species specific and not well studied. Their reactions are categorized into stinging and pruritic-causing [13]. Stinging pain usually results in burning sensations, swelling and vesicle formation whereas pruritic reactions are from contact with non-venomous urticating hairs that results in mechanical irritation. Hence, it is not advisable to touch hairy caterpillars for this very reason [13].

\subsection{Myriapods}

Both centipedes (Chilopoda) and millipedes (Diplopoda) are classified under 
this subphylum. Centipedes (Chilopoda) own a venomous bite and are often predatory. Each segment only has a pair of legs with their bases far apart [14] (Figure 4). Fortunately, some centipede bites are too small to pierce human skin [14]. The poison is delivered through modified hollow legs just behind the head (forcipules) [11] [14]. Its length varies from 3 to $300 \mathrm{~mm}$ [11]. The only centipede of medical significance is from the genus Scolopendra [14].

Malaysia is home to 2 species, mainly the Scolopendra morsitans and the Scolopendra subspinipes. They are up to $20 \mathrm{~cm}$ in length and prefer staying in the dark [14]. Bites from these insects result in 2 puncture marks with bleeding, intense pain and local swelling following soon after [11] [14].

Millipedes (diplopoda) do not have poisonous bites and is primarily herbivorous (Figure 5). They curl up into a spiral when touched and most of the segment carries 2 pairs of legs with their bases close together in midline [14]. Their length varies from $20-300 \mathrm{~mm}$ [11]. Although it is not poisonous, it can secrete defensive fluids made up of hydrogen cyanide [11]. Prolonged contact with this fluid leads to burning sensation and subsequent blister formation [11] [13] [14].

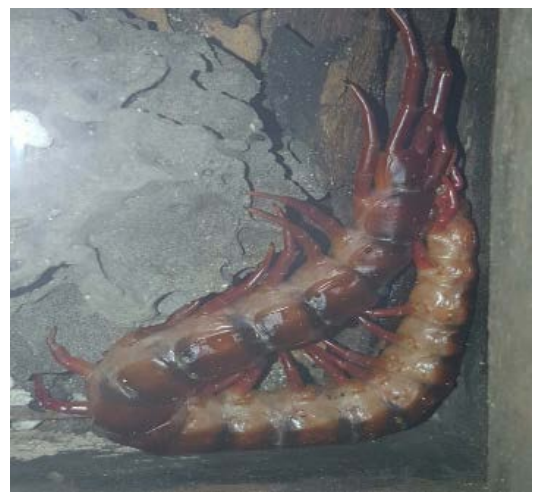

Figure 4. Scolopendra sp. Centipedes is easily distinguished by their segmented body, each of which contains a pair of legs, spread apart. Bites usually result in oedema, excruciating pain and fever.

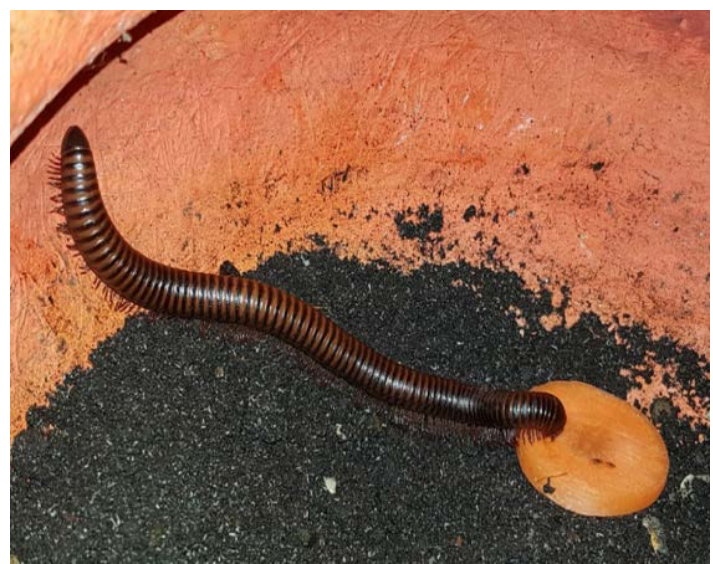

Figure 5. Thyropygus sp. Millipedes generally has 2 pair of legs on each segments, usually close together. They do not possess venom. 


\section{Marine Life Envenomations}

The world of marine ecosystems is overwhelmingly beautiful. Many creatures, all unique and distinctive, roam these waters. Fortunately, the vast majority of these creatures do not pose a significant threat to human as they are not naturally aggressive, reacting exclusively in defence. As such, marine venomous animals mainly employ various deceptive tactics such as hiding in crevices, camouflaging, distractions, having sharp tendrils or producing bright and vivid colours to suggest that they possess toxins. Best precautions touted by experts mainly revolve around zero contact above all or retreating away. An overwhelming majority of unwanted outcomes primarily result from accidental encounters with these animals such as touching, stepping, harassing or trespassing. From a public health perspective, information regarding the appearance, habitat, location of stinging apparatus and monitoring of these species in recreational waters is essential in avoiding envenomation [21].

\subsection{Cnidaria Toxin Containing Species: Jellyfish and Sea Anemone}

Cnidarians are one of the oldest lineages of venomous animals on the planet [22]. The Cnidaria sp. represents one half of the phylum group of the Coelenterata kingdom (The other member being the Ctenophora sp) [23]. They are responsible for more envenomations than any other phylum and therefore are of a tremendous public health significance. The Coelenterate kingdom is distinguished from other invertebrates in that they possess radial symmetry in structure [9]. Specifically, they have radial appendages that surround a gastrovascular cavity called a coelenteron that only has a single entrance [7] [22] [24].

The main difference between the sea anemone and the jellyfish is that sea anemone is polyps that are attached to a fixed structure whereas the Jellyfish encompasses medusa that float freely [24] (Figure 6). However, despite their basic anatomy, they have evolved to be able to subdue prey and repel predators efficiently [22]. Cnidarians are carnivores and they often are equipped with specialised cells called cnidocytes on their tentacles [7] [9]. These cnidocytes contain capsule-like structures called cnidae, which is a sharp thread that is discharged when touched [9]. These specialised envenoming apparatus have been likened to a "harpoon" by previous studies and the content of the venom includes many proteinaceous substances such as enzymes, pore forming toxins and neurotoxins [22]. Specifically in jellyfish and sea anemone, the venom is stored within a protein capsule called the nematocyst [9]. These transport vesicles are in turn synthesized from the golgi apparatus of specialised cells called nematocytes. These vesicles containing toxins will then be introduced into the integument of its prey by its firing cnidae to inject the toxin [7]. Figure 7 shows the anemonefish and sea anemones.

Often it is important to note that not all nematocytes discharge upon contact and jellyfish can retain their stinging potential weeks or months after death or being washed ashore [21] [23]. Amongst the hundreds of species of jellyfish, the 

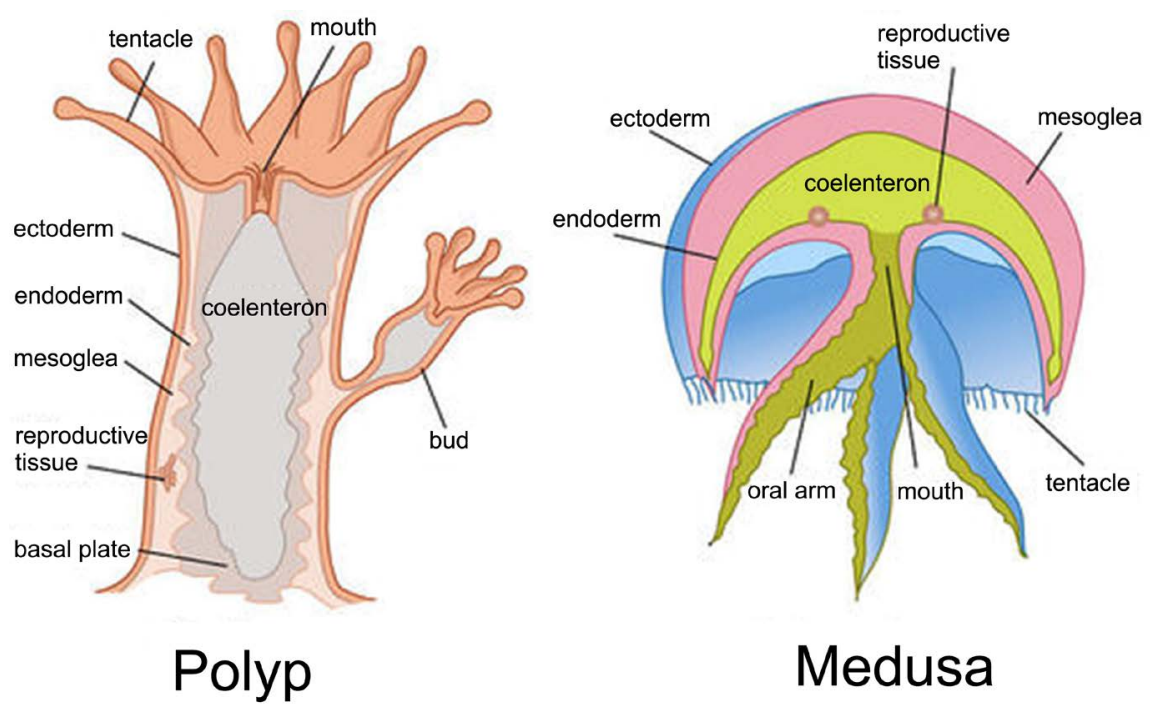

\section{Medusa}

Figure 6. The general cross-section of the Cnidaria Phylum (derived from Cnidarian Structure and Function, 2015, accessed from https://www.ck12.org/biology/Cnidarian-Structure-and-Function/lesson/Cnidarian-Struc ture-and-Function-Advanced-BIO-ADV/)

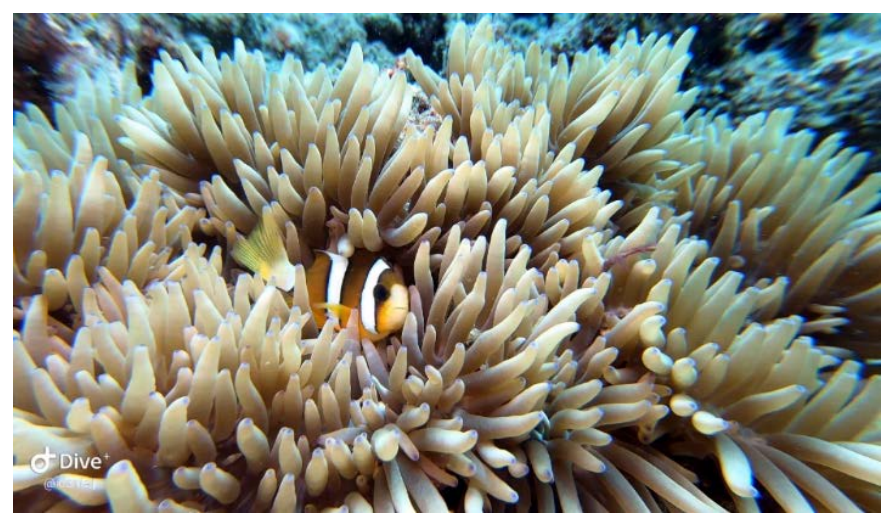

Figure 7. Anemonefish often inhabit sea anemones, where they live together in a mutual relationship. Though the sting of the anemone may not be harmful, it can be irritable and painful.

Major Box Jellyfish (Chironex fleckeri) is often cited as the most dangerous jellyfish, with an international report quoting at least 67 deaths occurring in North-west Australia and along the east coast of Queensland [6]. The venom of this species of jellyfish is very potent and it also has many tentacles that would increase surface of contact to human skin [23].

Other venomous species include the Portuguese Man-of-war (Physalia physalis), blue bottle jellyfish (Physalia utriculus) and the small Australian Irukandji Jellyfish (Carukia barnesi) found in the Atlantic, Pacific and South-East Asia [21]. In fact the Irukandji Jellyfish, much like the Major box Jelly fish, is associated with a high incidence of mortality amongst the venomous species [6].

Once stung, the area of affected skin would be in agonizing pain with pruritis and urticaria developing shortly after. The patient may be tachycardic from the 
pain, allowing the venom to rapidly permeate the body [21]. The venom also trigger histamine release from mast cells which account for tentacle print dermatitis [25]. This painful dermatitis is in part due to specific components in the venoms such as catecholamines, 5-hydroxytrptamine, fibrinolysins, cardiotoxins and histamines [4]. Various proteolytic and haemolytic proteins act to damage prey tissue, leading to haemorrhagic necrosis and ulceration [7] [22] [26]. Pore forming toxins enable membrane pores to lyse cells osmotically 26. Furthermore, catecholamine and 5-HT in the venom can induce vasodilatory or vasoconstrictive action in the capillary bed throughout the body, leading to an overall increased systemic absorption, accelerating the damage of the venom [22] [24] [26] [27].

A major sting is categorised as an envenoming area larger than $50 \%$ of the body surface area of the patient or involving more than two limbs which can result in extreme pain, tachycardia, fever, nausea, vomiting and abdominal colic [22] [23]. If enough venom spreads through the bloodstream, haemodynamic instability, respiratory distress, syncope, anaphylaxis or death may be a likely sequelae [24]. Neurological symptoms include seizures, myalgias, ataxia, vertigo, mononeuritis multiplex and coma [21]. These intriguing constellations of symptomology are often called the "Coelenterate syndrome" by some authors [26]. Some species of jellyfish can cause unique presentations in patients such as in the Irukandji syndrome of the Irukandji Jellyfish, characterised by a delayed lower back pain, abdominal cramping, headache, diaphoresis and tachycardia with significant hypertensive crisis later on [28].

Jellyfish venom tends to have a neurotoxic component, blocking the voltage-dependant sodium channels leading to muscle spasms, systemic weakness or paraesthesia (Figure 8). The severity of stings are unsurprisingly related to the potency of the venom of the considered species, the amount of tentacles that

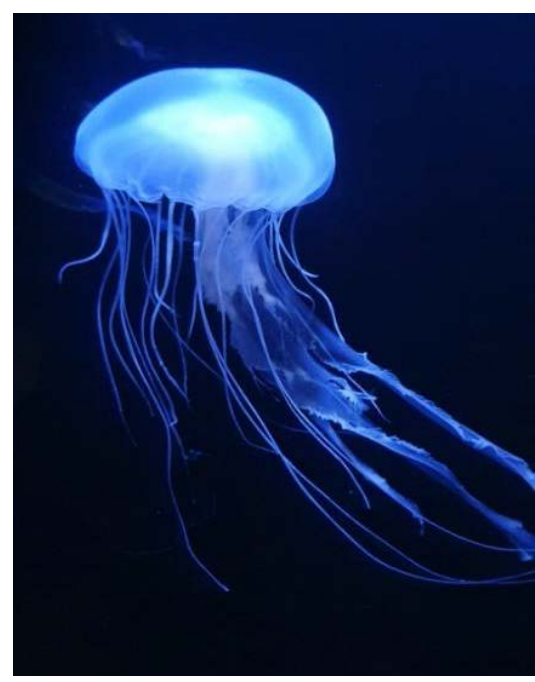

Figure 8. In many cases, envenomed victims do not even see the jellyfish due to its transparent nature of its built. To others, it may seem like a floating plastic or debris in the vast ocean. 
make contact with the skin and duration of contact [29]. Preventative measures to protect against envenomation include wearing suitable footwear, avoid swimming in waters with plenty of Cnidaria organisms and wearing full-length fitting suits [9]. The methods of treatment often revolve around the concept that these proteinaceous venoms are heat labile and can denature quickly once introduced to heat [26] [30]. Authors of a study advocated that heat applied to area of envenomation for either 20 mins at $48^{\circ} \mathrm{C}$ or 2 mins at $53^{\circ} \mathrm{C}$ was able to prevent death and suggested a continuous stream of hot as tolerable water for 10 to 20 minutes may help [31]. Adding vinegar, urea, sea water remained as the first line treatment since 1908 to prevent additional further discharge of the nematocytes, especially if tentacles are still attached [4] [6] [29]. However, the "famous" remedy of urinating on stinged tissue is likely a myth as while urine does contain ammonia and urea that can help in some stings, its quantities are biologically negligible. Plus, urinating on the envenomed region can trigger more firing of the envenoming and introduce unnecessary infections to patients [32]. A study conducted in 2012 showed that prophylactically applied sun cream containing jellyfish sting inhibitors reduced the risk of symptoms development post envenomation [33].

The stings of $C$. fleckeri are often life-threatening and early aggressive management may be required such as cardiopulmonary resuscitation with hospitalisation and anti-venom administration [29]. The Irukandji syndrome patients also require early hospitalisations with cardiac monitoring for evidence of myocardial injury and large doses of opioid analgesia or benzodiazepine for hypertension resolution [29].

\subsection{Sea Snakes}

All of the 50 species of sea snakes are venomous and can cause serious harm to humans if disturbed [9]. Most of them live mainly close inshore, reefs, around tropical and subtropical waters of the Indian and Pacific oceans [9] [24]. As luck would have it, these sea snakes are curious creatures that rarely bite but may become aggressive if distressed [9] [27]. Notably, the sea snake should not be taken lightly as its venom is registered to be 10 times more deadly than the already potent cobra venom [30].

Appearance wise, sea snakes differ from eels and the elapid species of snakes as the sea snake has scales, nostrils and a flattened body to enable swimming. The snake also possesses no fins or gills and has valve-like nostril flaps to prevent water from entering its nose [21] [24]. Sea snakes swim with its head above the surface and are sometimes seen on land but classically never far from the water.

These sea snakes (family Hydrophiidae) secrete a venom of composite mixture that results in various neurotoxic and myotoxic effects to the victim [21]. Neurotoxins of the sea snake are structurally similar to their terrestrial (Elapid) counterparts but differ radically in function. Functionally, sea snake venom acts 
postsynaptically and almost exclusively bind to the alpha subunits of oncotic receptors at the neuromuscular junction whereas the Elapid sp. can either act presynaptically (beta-bungarotoxin) or postsynaptically (alpha-bungarotoxin) [34]. Among the myotoxic compounds in the sea snake venom, Phospholipase- $\mathrm{A}$ is strongly implicated in the resulting mitochondrial toxicity and inhibition of acetylcholine production at the presynaptic nerve ending [21]. This results in reduced oxygen uptake within skeletal muscle mitochondria and subsequent myotoxic and neurotoxic symptomology [24] [35].

In its entirety, the clinical presentations in patients with sea snake envenomation include myalgia, vomiting, eye signs such as ptosis, opthalmoplegia, pupillary dilatation with poor pupillary reflex. The bite itself, as mentioned earlier, ranges from being virtually painless to mildly painful with a paucity of symptoms within a few minutes to hours. However, patients may insidiously develop euphoria, anxiety or restlessness later on as the venom gradually dominates the systemic circulation [21] [36]. In addition to that, there is also paralysis of the lower motor neuron, bulbar paralysis leucocytosis, myonecrosis, rhabdomyolysis and myoglobinuria which can all lead to secondary renal failure, hyperkalemia and even convulsions [30]. The area of envenomation can go on to result in gross tissue damage requiring amputation [9].

The appearance of the Malayan krait (Bungarus candidus) is black with white bands throughout its body (Figure 9). It has a potent neurotoxin venom with a lethal dose $\mathrm{LD}_{50}$ of $0.1 \mu \mathrm{g} / \mathrm{g}$. Its venom constituents include phospholipase $\mathrm{A}$ toxin and 2 different polypeptide toxins [37]. The major lethal toxin found in these species is known as candidus toxin, which accounts for the neurologic sequelae and myotoxicity [37].

Another species to be concerned about is the banded krait (Bungarus fasciatus). It is very much similar to the Malayan krait, except it usually has yellow bands in place of the known white bands of the Malayan krait [37] [38]. It is generally a shy species that does not attack unless disturbed. Its venom is a cocktail of multiple postsynaptic neurotoxins, ceruleotoxin (phospholipase A2 neurotoxin), presynaptic neurotoxins and cardiotoxin [37].

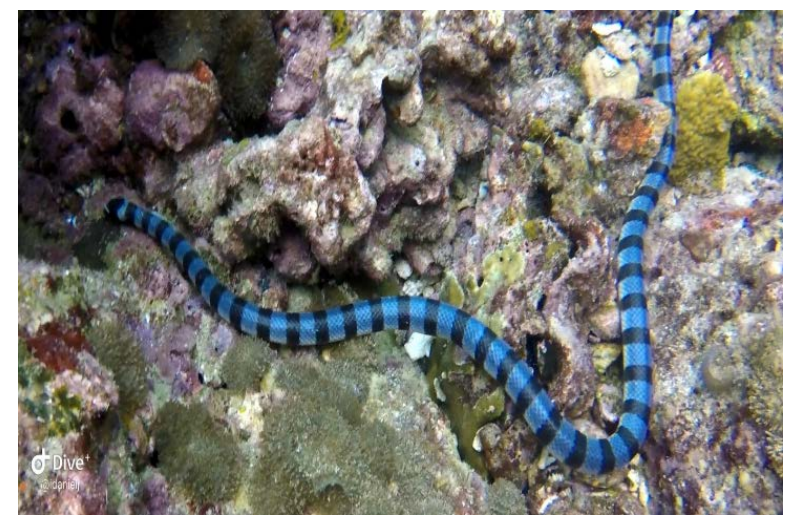

Figure 9. The Malayan krait (Bungarus candidus) is widely distributed across the waters of Malaysia. 
Known for being a particularly aggressive species, the beaked sea snake (Enhydrina Schistosa) is uniformly grey above its midline with a creamish white coloration below [38]. It has a characteristic beaked nose with stripes running from head to tail [38]. Asides for being a highly belligerent snake, its venom concoction, calculated to have a lethal dose (LD50) of less than $0.1 \mu \mathrm{g} / \mathrm{g}$, is made of at least seven extremely lethal basic phospholipase A and two acidic phospholipase A2. Severe myotoxic effects occur to the patient following envenomation [37].

Safety measures cited by the WHO include shuffling the feet when traversing lagoons or shallow waters, wear thick boots and if possible travel with anti-venom especially in snake-infested waters. These measures are exceedingly important as most snake bites happen on the lower limbs of the inhabitants of rural or coastal areas [4] [9] [39]. First aid post-envenomation involves pressure immobilization in situ (not tourniquet) until reaching medical facilities as this prolongs venom spread [39]. Anti-venom is manufactured by the Commonwealth Serum Laboratories (CSL) in Australia and parts of Malaysia and the recommended dosage is 1000 units [4]. The preferred anti-venom includes serum from sea snake (Enhydria schistose) and can be given as either a monovalent or polyvalent preparations. However, the monovalent elapid tiger snake anti-venom ( $N$. scutalus) can be used if sea snake anti-venom is not immediately available [30]. The overall rate of mortality for patients that are bitten is around $50 \%$ but reduces to $3 \%$ if anti-venom is given within 48 hours of envenomation [30]. It is also important to note that despite of the poor prognosis relating to some of these envenomations, less than $25 \%$ of those bitten actually express these symptoms as sea snakes have inefficient fangs and inject low volumes of venom into the patient [30]. Supportive measures such as intubation and mechanical ventilation with correction of any hyperkalaemia are essential treatment avenues to address [36].

\subsection{Blue-Ringed Octopus and Other Tetrodotoxin Containing Species}

The Blue-ringed octopuses casually rank amongst the deadliest animals in the sea with several fatal bites reported each year (Figure 10). They inhabit the shallow waters throughout the Australia and Eastern Indo-Pacific regions including some coastal waters of Malaysia. Out of approximately 650 known species of blue ringed octopus, only 2 are considered venomous, specifically the Australian blue-ringed octopus (Hapalochlaena lunulata) and the Australian spotted octopus (Hapalochlaena maculosa) [30]. Its lethality can be attributed to Tetrodotoxin (TTX) and anhydrotetrodotoxin (which can be converted to TTX) [4] [6] [21].

TTX is one of the most potent non-protein toxins known to man [4]. This compound is synthesized by the Vibrionaceae family of bacteria and serve to inhibit the action potential of various voltage-gated sodium channels in many tissues of the body without affecting the resting membrane potential of the other ion channels [21] [40]. When harassed, the octopus flashes around 60 iridescent 


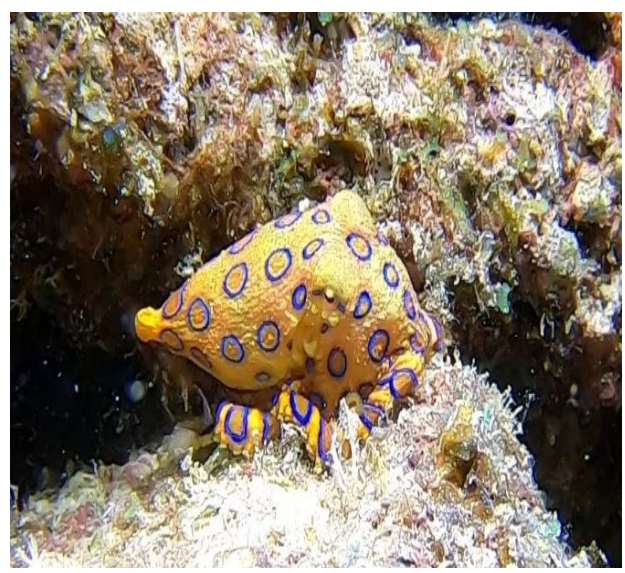

Figure 10. The blue ringed octopus (Hapalochlaena lunulata) uses its bright and vivid coloration as a means of warning off predators.

blue rings around its mantle, head and arms in an aposematic warning display [8]. If the animal is further harassed or handled, it empties its venom into its pharynx and bite painlessly with a pair of chitinous jaws at the base of its tentacles [6] [24].

The clinical syndrome arising from these bites are mainly neurotoxic and cardiotoxic in nature, with symptoms beginning within several minutes to hours [4] [21]. Specifically, nausea and abdominal pain may occur, usually without vomiting. In addition, some patients may also present with a relative paucity of gastrointestinal symptoms as well. Nonetheless, neurotoxic effects may occur rapidly thereafter, within $10-45$ minutes and present with dizziness, weakness, paraesthesia of the lips, tongue, throat and limbs [4]. Cardiotoxic effects include tachycardia, arrhythmias and hypotension with additional symptoms of cyanosis, dyspnoea, pallor, diaphoresis and increased ptyalism [4] [41]. An ascending paralysis (bulbar and limb) is often observed, leading to eventual respiratory depression in as little as 40 minutes to 5 hours [6] [9] [41]. The resultant hypoxemia of respiratory paralysis may lead to convulsions and various forms of brain hypoxic impairments as well [42]. Disseminated intravascular coagulopathy may also occur in the most severe of cases [41]. Fatality occurs at a rate of $50 \%$ to $80 \%$ within 20 to 30 minutes if left untreated [41] [42].

First aid is primarily pressure bandaging with immobilization with treatment being supportive [29]. Pre-emptive measures that should be taken by the individual include wearing suitable footwear when exploring shallow waters, avoid handling the blue ringed octopus and to warn others if the blue-ringed octopus is spotted [9]. In addition, many other organisms secrete TTX within specialised glands and have resistance to it via TTX resistant channels such as the pufferfish, the coloured frogs of Central America, Japanese Ivory shellfish, Trumpet Shellfish, Californian newts and some flatworms [41]. There is currently no commercially available antitoxin for Tetrodotoxin but a research report published in Toxicon illustrated that monoclonal antibodies specific to tetrodotoxin was in development and had successfully reduced lethality in mice subjects [43]. 


\subsection{Venomous Fish: Scorpaenidae Family, (Stonefish, Scorpionfish)}

The family Scorpaenidae encompasses a vast cornucopia of fish, characterised by the presence of specialised spines as its venom apparatus [23]. Three distinct groups fall under the Scorpaenidae category: Pterois (lionfish, zebrafish), Scorpaena (Scorpionfish and bullrout) and finally Synanceia (stone fish) [23]. There are approximately 1200 species of fish that are venomous with around 200 of them having capacity to inflict clinically relevant stings [4].

The largest biodiversity of these animals is found in the tropical and subtropical seas of the world, with some dangerous species inhabiting the northern tropical oceans usually in the coastal areas [4] [9]. They are slow swimmers, often burying themselves in the seabed. Their venom apparatus is highly developed, primarily consisting of grooved spines harbouring venom-secreting tissue and is attached to the musculature underneath [21]. Most of the spines among these species of fish are concentrated dorsally. During envenomation, the venom glands compress to send the venom into the spines and into the wound of its victims [44]. Damaged spines can also regenerate but carry less venom than previously undamaged spines [24].

The toxicity of the Scorpion fish venom arises from the heat-labile properties it possesses and is somewhat similar to the Cnidaria sp. Essentially, the venom comprises of an intricate mixture of proteins such as hyaluronidase, which is thought to be a lot more potent compared to typical terrestrial snake venoms. It is responsible for the cytolytic events occurring post-envenomation which results in significant connective tissue necrosis and destruction [45]. The primary presenting complaint is pain which radiates centrally for the initial 2 hours and subsides over the next 12 hours [30]. Prominently, victims become pale, with oedema at the site of the envenomation, subsequently, vasospasms and cyanosis may take weeks or months to resolve [24]. Other associated complaints include vomiting, diarrhoea, sweating, cardiac arrhythmias, hypotension, muscle spasms, paralysis and fits [46] [47].

The Stonefish (Synanceia spp.) are infamous for being one of the world's most dangerous fish (Figure 11 and Figure 12). They are found throughout the world, especially in the Indo-Pacific waters [36]. The most venomous stonefish known to man is the estuarine stonefish (Synanceia horrida, syn. S. trachynis) [9]. They produce stonustoxin, which is both a haemolytic and a vasorelaxant, resulting in localized oedema and profound life-threatening hypotension [36]. Normally found in nature amongst the brown-green sea vegetation and sea bed stones, it is characteristically covered in slime that algae can grow on, providing exceptional camouflage rivalling other well-known inconspicuous species [6].

A case report carried out in North Borneo, Sabah had reported that a tourist presented to their hospital following stepping on a stone fish. The pain described was excruciating and did not subside despite reasonable treatment using intramuscular diclofenac, intravenous morphine and an ankle block. Subsequently, 


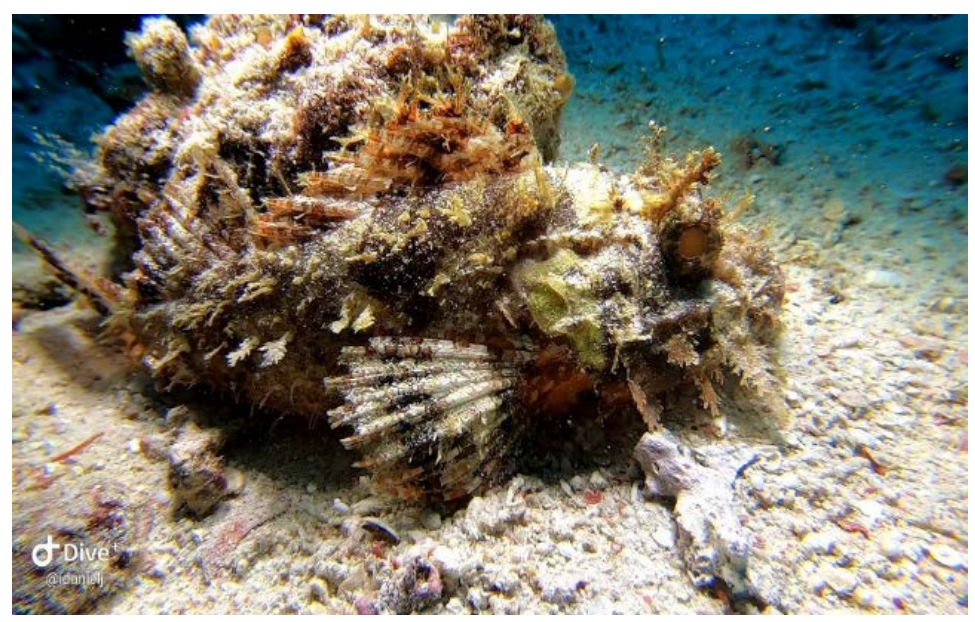

Figure 11. The stonefish are excellent in camouflaging with its surroundings. It uses this element of disguise as its main defence mechanism. Envenomation is associated with a high mortality rate.

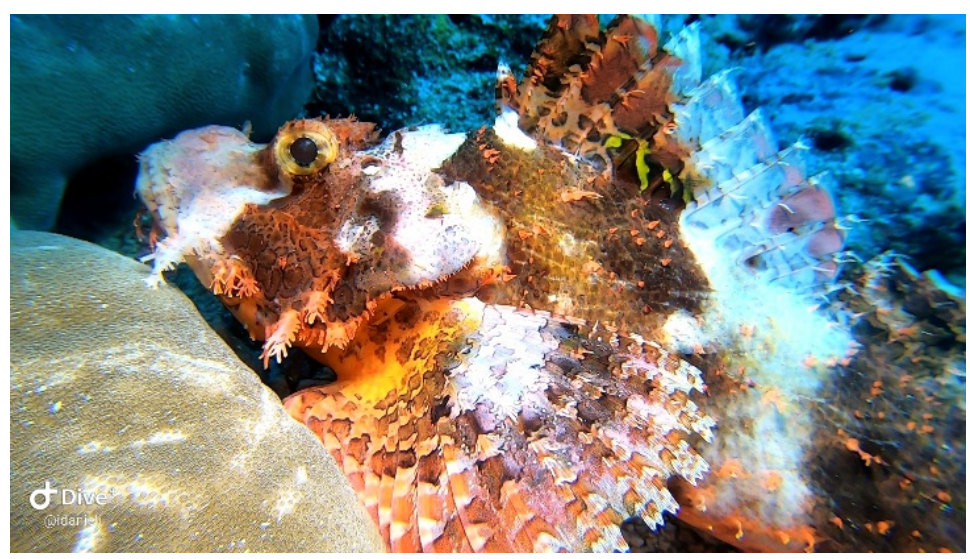

Figure 12. Yet another bottom dweller that is commonly found in Malaysia and other coastal waters, the devil stinger, which is a close relative of the true stonefish family. Again, as demonstrated, it is truly a master of disguise, blending with its surrounding.

the treating team had then immersed the foot in "as-hot-as-tolerated" water for 30 minutes with the patient's pain score dropping to an incredible $1 / 10$ within the hour without further treatment. This reflects the characteristic heat-lability of the Scorpaenidae and Synanceiidae venoms [46].

Unlike the stonefish, lionfish envenomation is not as severe (Figure 13). The lionfish are considered to be the least potent when it comes to toxicity in its family. It has been shown that warm water $\left(45^{\circ}\right)$ immersion can relieve pain and at the same time inactivates the toxin [47].

\subsection{Venomous Stings: Stingrays}

Stingrays, like sharks and skates, belong to the Chondrichthyes family and prominently feature broad and flat chests with whip like tails [23]. Stingrays are found throughout the world in tropical, subtropical and warm temperate oceans, from the Indo-Pacific to the Northern seas, around shallow intertidal waters, 


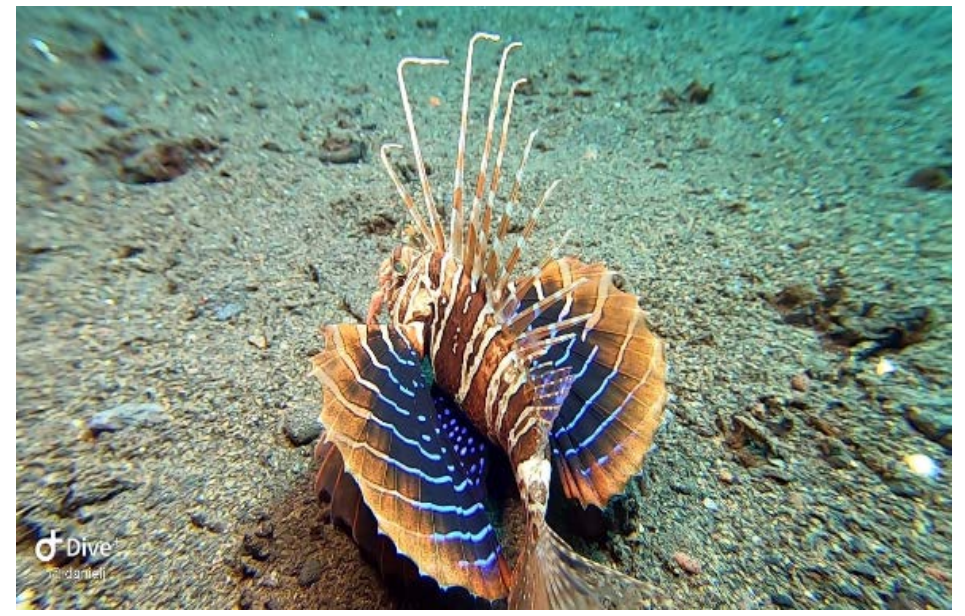

Figure 13. The lionfish (Pterosis spp.) possess venom that is very much less potent compared to the stonefish or scorpion fish.

lagoons, sandy areas and between reefs [21] [27] [48]. The spines on the stingray can cause pneumothorax and puncture of many thoracoabdominal organs [47]. Most sting ray "attacks" are more towards defence against unwanted human contact rather than intentional attacks [48]. The force of the sting is strong enough to penetrate thick rubber and the tail will reflexively whip its victim when its wings are disturbed. The typical anterior overhead angulation of its tail is its aggressive posture, indicating potential envenomation [24].

An envenomation from a sting ray naturally brings about intense and immediate pain accompanied by sialorrhoea, vomiting, diarrhoea, seizures, generalised oedema (if the wound penetrated the trunk), limb paralysis, bradycardia and shock [29] [30] [48]. The pain can go on to involve the entire limb, peaking around 30 to 60 minutes, radiating centrally and last for 2 days [36] [48]. The most severe complication following a sting ray envenomation is arterial laceration or spinal cord trauma. A retrospective review of 119 patients with sting ray envenomation described the clinical presentation and treatments used in an Emergency Department (ED) of San Diego, California. Their study found that $80 \%$ of patients were male with an average age of 28.3 years. $94 \%$ of all stings happened over the lower extremities and $97 \%$ of patients required some form of pain management. Agents used included Opioids and NSAIDS with all patients receiving hot water immersion therapy. A documented $88 \%$ of patients receiving hot water immersion as sole therapy for 30 minutes had reported improved pain relief without additional analgesia. Predictably, the study also demonstrated that wound infections occurred more frequently in patients who were not commenced on prophylactic antibiotics in ED [49].

Preventative measures to avoid unfavourable sting ray encounters include shuffling feet along sandy lagoons and wearing suitable thick footwear [9]. First aid manoeuvres include, removing victim from the water and applying local pressure to bleeds, immersing in hot water or heat packs to alleviate pain with eventual transfer to medical facilities [36]. Treatment includes appropriate anal- 
gesia, tetanus prophylaxis and surgical debridement of wound with appropriate irrigation. Local lidocaine without epinephrine has been recommended if heat failure is inadequate for pain control [21]. Removing an impaled spine worsens the injury as the natural design of the barbed spine is retroserrated bilaterally with jagged sharp cartilage pointing away from the tip of the spine. This allows for easy penetration but severe lacerations if removed hastily [48]. Venom is injected into its victim when the integumentary sheath of the spine is detached. Minor punctures rarely give anything more serious than cellulitis but severe wound injuries from envenomation can lead to rapid haemorrhage and necrosis of muscles and connective tissues.

However, mortality from these stings is often a result of penetrating injuries to the chest and abdomen, especially with cardiac injury leading to the highest mortality [29] [36]. Foreign body lodged inside victims can lead to serious secondary infections, necrotising fasciitis and even tetanus, as such it is recommended that all debris be removed to help with source control of infection [29] [36].

\subsection{Sea Urchins}

Sea urchins belong to a group called Echinoderms which are closely related to sea stars (Figure 14 and Figure 15). They possess either rounded or hollow tip

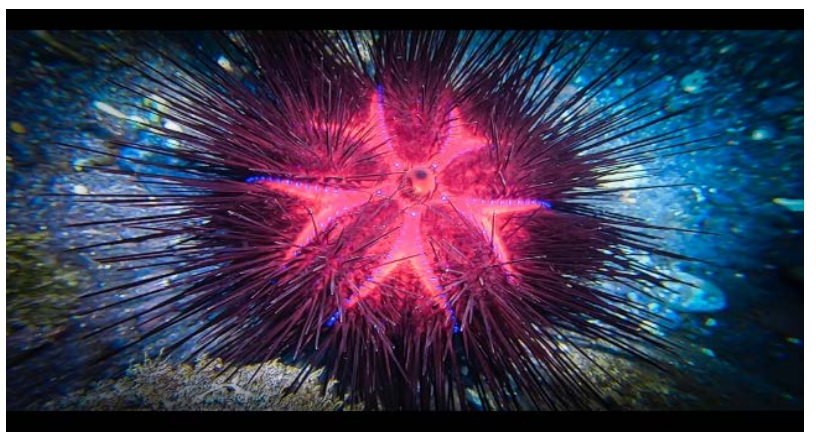

Figure 14. One of the species of sea urchins, with its bright display, possibly as a means to warn off predators.

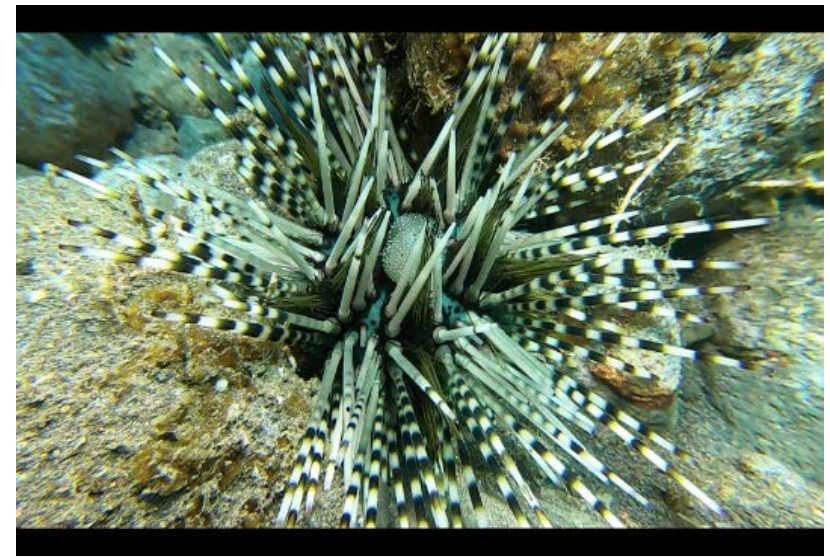

Figure 15. Another species of sea urchin commonly spotted in Malaysian waters. Their spines are able to penetrate the epidermis layer with relative ease. 
spines for envenomation. Typically, envenomation occurs via puncture wounds resulting in intense pain, bleeding and oedema with muscle aches following in the next 24 hours. Multiple toxins can be found in its venom including hemolysins, proteases and glycosides. Rarely, severe complications may occur including cardiovascular and respiratory collapse or tissue necrosis. Treatment generally involves removing the retained spine to prevent further envenomation and soaking the affected area in hot water $\left(40^{\circ} \mathrm{C}\right.$ to $\left.46^{\circ} \mathrm{C}\right)$ for 30 to 90 minutes, taking into account the heat liability of the toxins. Oral or even intravenous analgesia may be required to help control the pain [50].

\section{Conclusion}

The consensus following this review is that there is still a general lack of evidence based medicine to inform more robust intervention measures. Many of the recommended managements depend on the liability of the venom and general symptoms and source control strategies. However, regardless of evidence, certain steps are cornerstone to management and if followed faithfully, can greatly influence patient outcomes. First aid treatments have been shown to greatly impact the overall morbidity and mortality of patients. It serves to impede the flow of venom, buying precious time to salvage affected tissues and to institute more definite treatment. Species identification helps in prognosticating envenomation, aid anti-venom selection and helps the attending clinician to adequately anticipate oncoming toxicity complications. Finally, as with all other branches of medicine, continuous high yielding experiments and studies in the field of envenomations always serve better to the diagnostic capabilities and management skills of the treating physician leading to overall improvements in patient care.

\section{Funding}

No funding was used for this specific work.

\section{Acknowledgements}

We acknowledge every author that contributed to the study, with special thanks to Dr. Pillai for supervising and keeping us motivated. We also acknowledge the National Library of Malaysia which has a vast variety of literature and studies. Last but not least, we acknowledge Dr. I. Johan for his skilled photography of the animals.

\section{Conflicts of Interest}

The authors have declared that no competing interests exist in the culmination of this body of work.

\section{References}

[1] Nelsen, D.R., Nisani, Z., Cooper, A.M., Fox, G.A., Gren, E.C., Corbit, A.G., et al. 
(2014) Poisons, Toxungens, and Venoms: Redefining and Classifying Toxic Biological Secretions and the Organisms That Employ Them. Biological Reviews, 89, 450-465. https://doi.org/10.1111/brv.12062

[2] Hodgson, E. (2012) Chapter Fourteen: Toxins and Venoms. In: Ernest, H., Ed., Progress in Molecular Biology and Translational Science, Vol. 112, Academic Press, Cambridge, 373-415. https://doi.org/10.1016/B978-0-12-415813-9.00014-3

[3] Mebs, D. (2002) Venomous and Poisonous Animals: A Handbook for Biologists, Toxicologists and Toxinologists, Physicians and Pharmacists. MedPharm, Guildford.

[4] Magill, A.J., Strickland, G.T., Maguire, J.H., Ryan, E.T. and Solomon, T. (2012) Hunter's Tropical Medicine and Emerging Infectious Disease. Elsevier Health Sciences, Amsterdam. https://doi.org/10.1016/C2009-0-51934-4

[5] Berthé, R. (n.d.) Spitting Behaviour and Fang Morphology of Spitting Cobras.

[6] Fernandez, I., Valladolid, G., Varon, J. and Sternbach, G. (2011) Encounters with Venomous Sea-Life. The Journal of Emergency Medicine, 40, 103-112. https://doi.org/10.1016/j.jemermed.2009.10.019

[7] Lotan, A., Fishman, L., Loya, Y. and Zlotkin, E. (1995) Delivery of a Nematocyst Toxin. Nature, 375, Article No. 456. https://doi.org/10.1038/375456a0

[8] Mäthger, L.M., Bell, G.R.R., Kuzirian, A.M., Allen, J.J. and Hanlon, R.T. (2012) How Does the Blue-Ringed Octopus (Hapalochlaena lunulata) Flash Its Blue Rings? Journal of Experimental Biology, 215, 3752-3757. https://doi.org/10.1242/jeb.076869

[9] World Health Organization (2003) Guidelines for Safe Recreational Water Environments: Coastal and Fresh Waters. World Health Organization, Geneva.

[10] Snodgrass, R. (n.d.) Textbook of Arthropod Anatomy. Cornell University Press, New York.

https://cornellopen.org/9781501740794/textbook-of-arthropod-anatomy/

[11] Klaassen, C.D. and Amdur, M.O. (1996) Casarett and Doull's Toxicology: The Basic Science of Poisons. McGraw-Hill, New York.

[12] Itis.gov. (2020) ITIS Standard Report Page: Arthropoda. https://www.itis.gov/servlet/SingleRpt/SingleRpt?search topic=TSN\&search value $=$ 82696\#null

[13] Goldfrank, L., Flomenbaum, N. and Lewin, N. (2004) Goldfrank's Toxicologic Emergencies, ed 3. Annals of Emergency Medicine, 242, 149.

[14] Tweedie, M. (1995) Poisnonous Animals of Malaysia. Graham Brash, Singapore.

[15] Muslimin, M., Wilson, J.-J., Ghazali, A.-R.M., Braima, K.A., Jeffery, J., Wan-Nor, F., et al. (2015) First Report of Brown Widow Spider Sightings in Peninsular Malaysia and Notes on Its Global Distribution. Journal of Venomous Animals and Toxins including Tropical Diseases, 21, 11.

[16] Vetter, R. (2021) Brown Widow Spider. Center for Invasive Species Research. https://cisr.ucr.edu/invasive-species/brown-widow-spider

[17] Kim, C.M. (2013) Apitherapy-Bee Venom Therapy. In: Grassberger, M., Sherman, R., Gileva, O., Kim, C. and Mumcuoglu, K., Eds., Biotherapy-History, Principles and Practice, Springer, Dordrecht, 77-112.

https://doi.org/10.1007/978-94-007-6585-6 4

[18] Xie, C., Xu, S., Ding, F., Xie, M., Lv, J., Yao, J., et al. (2013) Clinical Features of Severe Wasp Sting Patients with Dominantly Toxic Reaction: Analysis of 1091 Cases. PLoS ONE, 8, e83164. https://doi.org/10.1371/journal.pone.0083164 
[19] Farrar, J., Hotez, P., Junghanss, T., Kang, G., Lalloo, D. and White, N.J. (2013) Manson's Tropical Diseases E-Book. Elsevier Health Sciences, Amsterdam.

[20] Rayamane, A., Kumar, M.P., Kishor, D.G., Dayayanada, R. and Saraf, A. (2014) Honey Bee Stings and Anaphylaxis: Review. Journal of Forensic Medicine, Science and Law, 23, 1-7.

[21] Watters, M.R. and Stommel, E.W. (2004) Marine Neurotoxins: Envenomations and Contact Toxins. Current Treatment Options in Neurology, 6, 115-123. https://doi.org/10.1007/s11940-004-0021-8

[22] Jouiaei, M., Yanagihara, A.A., Madio, B., Nevalainen, T.J., Alewood, P.F. and Fry, B.G. (2015) Ancient Venom Systems: A Review on Cnidaria Toxins. Toxins, 7, 2251-2271. https://doi.org/10.3390/toxins7062251

[23] Burnett, J.W., Fenner, P.J. and Rifkin, J.F. (1996) Venomous and Poisonous Marine Animals: A Medical and Biological Handbook. University of New South Wales Press, Randwick.

[24] Watters, M.R. (2005) Tropical Marine Neurotoxins: Venoms to Drugs. Seminars in Neurology, 25, 278-289. https://doi.org/10.1055/s-2005-917664

[25] Cormier, S.M. (1981) Physalia Venom Mediates Histamine Release from Mast Cells. Journal of Experimental Zoology, 218, 117-120. https://doi.org/10.1002/jez.1402180202

[26] Mariottini, G.L. and Pane, L. (2013) Cytotoxic and Cytolytic Cnidarian Venoms. A Review on Health Implications and Possible Therapeutic Applications. Toxins, 6, 108-151. https://doi.org/10.3390/toxins6010108

[27] Thangaraj, S., Bragadeeswaran, S., Sri Kumaran, N. and Suguna, A. (2016) Analgesic and CNS Depressant Activities of Sea Anemone Heteractis Aurora Nematocyst Toxin. Central Nervous System Agents in Medicinal Chemistry, 16, 162-172. https://doi.org/10.2174/1871524916666160129101049

[28] Fenner, P., Williamson, J., Callanan, V. and Audley, I. (1985) Further Understanding of, and a New Treatment for, "Irukandji" (Carukia barnesi) Stings. Medical Journal of Australia, 145, 569-574. https://doi.org/10.5694/j.1326-5377.1986.tb139500.x

[29] Berling, I. and Isbister, G. (2015) Marine Envenomations. Australian Family Physician, 44, 28-32.

[30] Watters, M. and Cannard, K. (1999) Marine Neurotoxins. In: Chopra, J.S. and Sawhney, I.M.S., Eds., Neurology in Tropics, Churchill Livingstone, New Delhi, 45-68.

[31] Carrette, T.J., Cullen, P., Little, M., Peiera, P.L. and Seymour, J.E. (2002) Temperature Effects on Box Jellyfish Venom: A Possible Treatment for Envenomed Patients? Medical Journal of Australia, 177, 654-655. https://doi.org/10.5694/j.1326-5377.2002.tb05000.x

[32] Tonseth, K.A., Andersen, T.S., Pripp, A.H. and Karlsen, H.E. (2012) Prophylactic Treatment of Jellyfish Stings-A Randomised Trial. Tidsskrift for den Norske laegeforening. Tidsskrift for praktisk medicin, ny raekke, 132, 1446-1449. https://doi.org/10.4045/tidsskr.11.0652

[33] Montgomery, L., Seys, J. and Mees, J. (2016) To Pee, or Not to Pee: A Review on Envenomation and Treatment in European Jellyfish Species. Marine Drugs, 14, Article No. 127. https://doi.org/10.3390/md14070127

[34] Tu, A. (1991) Handbook of Natural Toxins: Reptile Venoms and Toxins. CRC Press, Boca Raton. 
[35] Taub, A.M. and Elliott, W.B. (1964) Some Effects of Snake Venoms on Mitochondria. Toxicon, 2, 87-92. https://doi.org/10.1016/0041-0101(64)90008-X

[36] Winkel, K. and Nimorakiotakis, B. (2003) Marine Envenomations. Part 2-Other Marine Envenomations. Australian Family Physician, 32, 975-979.

[37] Kumar, T., Jayaraman, G., Lee, C.S., Arunkumar, A., Sivaraman, T., Samuel, D., et al. (1997) Snake Venom Cardiotoxins-Structure, Dynamics, Function and Folding. Journal of Biomolecular Structure and Dynamics, 15, 431-463. https://doi.org/10.1080/07391102.1997.10508957

[38] Tan, N.H. (2015) The Medically Important Poisonous Snakes of Malaysia.

[39] Baldé, M.C., Chippaux, J.-P., Boiro, M.Y., Stock, R.P. and Massougbodji, A. (2013) Use of Antivenoms for the Treatment of Envenomation by Elapidae Snakes in Guinea, Sub-Saharan Africa. Journal of Venomous Animals and Toxins including Tropical Diseases, 19, Article No. 6. https://doi.org/10.1186/1678-9199-19-6

[40] Schaumburg, H.H., Spencer, P.S. and Ludolph, A. (2000) Experimental and Clinical Neurotoxicology. Oxford University Press, Oxford.

[41] Watters, M.R. (1995) Organic Neurotoxins in Seafoods. Clinical Neurology and Neurosurgery, 97, 119-124. https://doi.org/10.1016/0303-8467(95)00015-C

[42] Stommel, E.W. and Watters, M.R. (2004) Marine Neurotoxins: Ingestible Toxins. Current Treatment Options in Neurology, 6, 105-114.

https://doi.org/10.1007/s11940-004-0020-9

[43] Rivera, V.R., Poli, M.A. and Bignami, G.S. (1995) Prophylaxis and Treatment with a Monoclonal Antibody of Tetrodotoxin Poisoning in Mice. Toxicon, 33, 1231-1237. https://doi.org/10.1016/0041-0101(95)00060-Y

[44] Burnett, J. (1998) Aquatic Adversaries: Stonefish. Cutis, 62, 269-270.

[45] Khoo, H.E. (2002) Bioactive Proteins from Stonefish Venom. Clinical and Experimental Pharmacology and Physiology, 29, 802-806. https://doi.org/10.1046/j.1440-1681.2002.03727.x

[46] Darlene, F.O. and Phee-Kheng, C. (2013) Hot Water Immersion as a Treatment for Stonefish Sting: A Case Report. Malaysian Family Physician, 8, 28-32.

[47] Warrell, D.A. (2016) Venomous Animals. Medicine, 44, 120-124. https://doi.org/10.1016/j.mpmed.2015.11.001

[48] Auerbach, P.S. (1991) Marine Envenomations. The New England Journal of Medicine, 325, 486-493. https://doi.org/10.1056/NEJM199108153250707

[49] Clark, R.F., Girard, R.H., Rao, D., Ly, B.T. and Davis, D.P. (2007) Stingray Envenomation: A Retrospective Review of Clinical Presentation and Treatment in 119 Cases. The Journal of Emergency Medicine, 33, 33-37. https://doi.org/10.1016/j.jemermed.2007.03.043

[50] Gelman, Y., Kong, E.L. and Murphy-Lavoie, H.M. (2019) Sea Urchin Toxicity. StatPearls Publishing, Treasure Island. 